\title{
"Se a base da educação é a mesma, as oportunidades também serão”? A propaganda sobre educação no governo Temer
}

\author{
Ronaldo Adriano de Freitas 1 \\ Silmara Dela Silva ${ }^{2}$ \\ A propaganda não é mais um negócio militar: ela torna-se a preocupação número um de um \\ Estado cuja política é, no essencial, determinada no exterior.... \\ Michel Pêcheux, Foi propaganda mesmo que você disse?, [1979]. 2011.
}

Resumo: Este artigo apresenta uma reflexão teórico-analítica acerca do funcionamento da propaganda governamental sobre educação no Brasil, durante a presidência de Michel Temer. O corpus de análise é constituído por uma peça publicitária a respeito da Base Nacional Curricular Comum (BNCC), com ampla circulação na mídia, em 2017. Tomando como ponto de partida reflexões propostas por Pêcheux acerca do funcionamento das propagandas de governo na formação social capitalista, as análises apontam como, na referida propaganda, se constitui um imaginário de democracia e cidadania relacionados à BNCC, tomada como capaz de reverter os quadros de desigualdade social no país.

Palavras-chave: Análise de discurso. Educação. BNCC. Propaganda governamental.

Abstract: This article presents a theoretical-analytical reflection about the functioning of government educational advertising in Brazil, during Michel Temer's presidency. The corpus of analysis consists of an advertising piece regarding the National Curricular Common Base (BNCC), with wide circulation in the media in 2017. Considering the reflections proposed by Pêcheux on the functioning of government advertising in capitalist social formation, the analysis shows how, in the advertising piece, it is an imaginary of democracy and citizenship related to the BNCC, taken as capable of reversing the picture of social inequality in the country.

Keywords: Discourse Analysis. Education. BNCC. Government advertising.

Resumen: Este artículo presenta una reflexión teórico-analítica acerca del funcionamiento de la propaganda gubernamental sobre la educación en Brasil, durante la presidencia de Michel Temer. El corpus de análisis es constituido por una pieza publicitaria en relación a la Base

1 Doutorando em Estudos de Linguagem na Universidade Federal Fluminense e professor do Instituto Federal de Educação Ciência e Tecnologia Fluminense.

2 Professora Adjunta da Universidade Federal Fluminense (UFF). Doutora em Linguística pela UNICAMP com estágio de Pós-Doutorado no Departamento de Ciências da Linguagem da UFF. 
Nacional Curricular Común (BNCC), con amplia circulación en la media, en 2017. Tomando como punto de partida reflexiones propuestas por Pêcheux acerca del funcionamiento de las propagandas del gobierno en la formación social capitalista, los análisis apuntan como, en la referida propaganda, un imaginario de democracia y ciudadanía relacionado a la BNCC, tomada como capaz de revertir los cuadros de la desigualdad social en el país.

Palabras clave: Análisis de discurso. Educación. BNCC. Propaganda gubernamental.

Neste artigo voltamo-nos à propaganda sobre educação no Brasil durante o governo de Michel Temer, propondo uma análise discursiva de seu funcionamento. Para isso, tomamos como corpus de análise uma peça publicitária sobre o lançamento da Base Nacional Comum Curricular (BNCC) para o ensino fundamental, posta em circulação no Brasil no ano de 2017, por ocasião da homologação do referido documento.

Na epígrafe que trazemos para este artigo, retomamos uma afirmação de Michel Pêcheux a respeito do funcionamento da propaganda em seu tempo, na qual o autor se volta, especificamente, à propaganda governamental. Em uma visada histórica a respeito de tais práticas na esfera capitalista, ao final da década de 1970, Pêcheux (2011 [1979], p. 74) aponta a passagem da propaganda governamental - inicialmente considerada "um elemento indispensável no prosseguimento das operações militares contra o inimigo exterior" - a uma ação interna, destinada ao convencimento da população a respeito da relevância e da pertinência dos variados atos de um governo. É desse modo que, em sua avaliação, a propaganda deixa de ser um negócio militar, tornando-se preocupação primordial dos governos na formação social capitalista.

Como Pêcheux (2011 [1979], p. 8o), entendemos que pensar a propaganda na formação social capitalista requer "fazer história". No Brasil, a chegada de Michel Temer à Presidência, interinamente em 12 maio de 2016, não se deu sem o lançamento de seu plano de governo ainda em 2015 - sob a denominação de "Uma ponte para o futuro" (PMDB, 2015) - documento que, tomado como agenda programática a partir do apossamento do vice ao cargo maior, firma um compromisso com a cartilha neoliberal de redução de gastos governamentais, citando a educação única e friamente para defesa da desvinculação das verbas constitucionalmente garantidas ao setor. Como afirmado no documento: "Para isso [atingir o equilíbrio das contas públicas] é 
necessário em primeiro lugar acabar com as vinculações constitucionais estabelecidas, como no caso dos gastos com saúde e com educação” (PMDB, 2015, p. 10).

Assim, ao iniciarmos nosso percurso pela epígrafe pechetiana, entendemos que a reflexão trazida pelo autor continua a produzir efeitos em nossos dias. O modus operandi da colocação em prática dessa agenda neoliberal é marcado pela intensa circulação de propagandas que apresentam as reformas (constitucional de limitação de gastos, trabalhista, previdenciária, educacional...) como necessárias, urgentes e benfazejas, sendo notória a circulação de propagandas do governo federal na imprensa e em emissoras de rádio e televisão, bem como são expressivos os custos desses investimentos em publicidade ${ }^{3}$.

Ao desenvolvermos nosso percurso, começamos por pensar as condições de produção do discurso publicitário governamental, retomando as reflexões de Pêcheux (2011 [1979]), bem como a legislação que regulamenta as práticas publicitárias do governo brasileiro. Retomamos também o discurso sobre a publicidade no campo de estudos da Comunicação Social, de modo a pensarmos historicamente sobre o modo como se constituem efeitos de sentidos para tais práticas, em nosso contexto sócio histórico.

Em um segundo momento, situamos a proposta de elaboração de uma Base Nacional Curricular Comum no atual momento político para passarmos à análise do corpus, constituído pela propaganda em vídeo disponibilizada na página no YouTube do Ministério da Educação, sob o título "Base Nacional Comum Curricular" (BRASIL, 2017b), a qual gozou de ampla circulação na mídia (TV, rádio, pontos de mídia de circuitos de aeroportos e eventos etc.). Entendemos que sua ampla circulação é emblemática do funcionamento da propaganda governamental sobre as políticas públicas estipuladas pelo Governo Federal no citado período e marca o modo pelo qual a educação é publicitariamente tomada nessas incursões.

\section{Publicidade (d)e governo: uma prática discursiva}

\footnotetext{
${ }^{3}$ Segundo dados públicos disponibilizados no Portal da Secretaria de Comunicação Social da Presidência da República (SECOM), no ano de 2017 foram gastos $\mathrm{R} \$ 205.730 .524,62$ em execução contratual de publicidade, destinadas a pagamentos para agências de propaganda (BRASIL, 2018).
} 
Ao refletir acerca das propagandas de governo e seu funcionamento, Pêcheux (2011 [1979], p. 74) propõe um distanciamento em relação às práticas tradicionais de se pensar tais propagandas em seu tempo, que costumavam considerá-las "evidentemente, um negócio de psicologia" (itálico do autor). Isso porque, conforme nos alerta Pêcheux, embora as propagandas sejam feitas de "imagens e palavras, sentimentos, ideias e gestos" (2011 [1979], p. 74), sua abordagem a partir dos efeitos psicológicos que produzem nos sujeitos ou simplesmente partindo-se das técnicas que subjazem sua prática é insuficiente para discorrer sobre o seu funcionamento discursivo, um funcionamento ao mesmo tempo linguístico e histórico.

Deslocando-se em relação às abordagens psicologizantes da propaganda - que se voltam a sua capacidade de manipulação sobre os sujeitos -, e, também, às explicações sobre as técnicas implicadas em sua produção e circulação, Pêcheux (2011 [1979], p. 80) propõe uma visada histórica acerca dessas práticas publicitárias, de modo a pensar aquilo que entende como sendo uma "história política da propaganda no desenvolvimento capitalista”. A seu ver, as práticas publicitárias, como todas as outras, decorrem do modo de produção capitalista $\mathrm{e}(\mathrm{m})$ suas contradições, o que consequentemente leva-o a questionar se os efeitos psicológicos e as técnicas concernentes às ações publicitárias não estariam relacionadas às formas históricas de assujeitamento decorrentes do próprio capitalismo, em suas maneiras de "gerir" "os corpos e as práticas" (PÊCHEUX, 2011 [1979], p. 80), no caso, as práticas de se fazer publicidade.

É nessa perspectiva proposta por Pêcheux que situamos a nossa reflexão, ao propormos pensar a relação entre publicidade e governo historicamente, e considerando as propagandas governamentais enquanto práticas discursivas, ou seja, práticas de produção de efeitos de sentidos que se dão para e por sujeitos, em uma determinada conjuntura sócio-histórica. Entendemos, assim, que as propagandas sobre educação veiculadas pelo Governo Federal são discursos e, enquanto tal, devem ser analisadas considerando-se a relação entre a sua materialidade específica e sua inscrição na história. 
Como afirma Pêcheux (1997b [1969], p. 79, itálicos do autor), “é impossível analisar um discurso como um texto, isto é, como uma sequência linguística fechada sobre si mesma, mas que é necessário referi-lo ao conjunto de discursos possíveis", considerando-se suas condições de produção. Conforme Orlandi (2001), em sua retomada de Pêcheux, são parte das condições de produção do discurso o contexto sócio-histórico que o determina, ou seja, as condições sócio-históricas de sua produção. No caso da propaganda governamental no Brasil, que ora nos interessa, importa-nos a sua constituição histórico-discursiva, bem como a legislação vigente, que determinam o seu modo de funcionamento na atualidade.

Nos estudos da área de Comunicação Social, além da exposição das técnicas voltadas à elaboração das peças e campanhas publicitárias, são frequentes as abordagens acerca da publicidade e propaganda a partir de classificações. Pinho (1990, p. 19), em obra que atualmente se encontra em sua sexta edição, ao propor o estudo acerca das propagandas institucionais, reserva o termo propaganda ao que especifica como sendo uma ação voltada à "divulgação de ideias", trabalho do profissional de relações públicas; diferenciando-a, assim, da publicidade, esta destinada à "promoção de produtos e serviços" (PINHO, 1990, p. 16).

Ao traçar um histórico dessas propagandas, Pinho (1990) faz menção à origem desse sentido de propagar que, conforme seu estudo, teria sido empregado inicialmente pela Igreja Católica no século XVII, associado à criação da Comissão Cardinalícia para Propagação da Fé, pelo Papa Gregório XV. O caráter religioso das propagandas em sua origem seria suplantado, segundo o autor, após a Revolução Industrial, época em que, em seus termos, a “difusão de novas ideias, princípios e doutrinas (...) deixou de ser exclusividade dos sacerdotes e se tornou uma atividade peculiar a vários tipos de organizações econômicas, sociais e políticas" (PINHO, 1990, p. 20). As propagandas deslocam-se, assim, de práticas exclusivamente religiosas para assumir um funcionamento relacionado ao político e ao mercado.

Ao propor uma classificação dos tipos de propagandas, o autor conceitua da seguinte forma aquela que chama de propaganda governamental:

Tem por objetivo criar, reforçar ou modificar a imagem de um determinado governo, dentro ou fora de suas fronteiras. A propaganda governamental feita pelo próprio governo ou por companhias estatais - representa uma 
grande parcela do volume total de propaganda veiculada no Brasil, o que demonstra a preocupação do governo (em seus três níveis: federal, estadual e municipal) com a opinião pública. (PINHO, 1990, p. 23).

Na descrição acerca das especificidades da propaganda governamental, o autor que já sinalizava para o impacto dessas propagandas no total de anúncios em circulação no país, põe em destaque o seu objetivo, voltado à produção e/ou readequação de uma imagem do governo.

Da perspectiva teórico-metodológica que adotamos, sabemos que todo discurso é presidido por um jogo imaginário, ou seja, um mecanismo de projeções de imagens para os sujeitos em suas posições discursivas, bem como para os referentes, entendidos como sendo aquilo sobre o que se diz. Segundo Pêcheux (1997b [1969], p. 85), trata-se de "representações imaginárias das diferentes instâncias do processo discursivo", que resultam "de processos discursivos anteriores (provenientes de outras condições de produção)" (itálicos do autor), constituindo, assim, as formações imaginárias. No caso das propagandas de governo, temos o próprio governo dizendo de si e/ou de seus feitos, buscando invariavelmente produzir para si e suas práticas uma imagem positiva.

Especificamente na propaganda que constitui nosso corpus de análise, temos um dizer do governo, ali representado pelo Ministério da Educação, sobre mudanças propostas no sistema educacional brasileiro. No discurso, busca-se projetar, assim, imagens positivas acerca do governo e dessas suas ações na área da Educação. Não se trata, no entanto, de qualquer governo, mas do governo de Michel Temer, que assume o posto após o golpe que culminou com a deposição de Dilma Rousseff da Presidência da República (Cf.: MATTOS; BESSONE; MAMIGONIAN, 2016). Trata-se de um governo com baixíssimo índice de aprovação junto à população brasileira, como registra pesquisa realizada pelo Ibope em dezembro de 2017, na qual se constatou a aprovação do governo por 6\% da população, e sua desaprovação por 74\% (VERDÉLIO, 2017). As propagandas, nesse caso, tornam-se primordiais na tentativa de se modificar a imagem do governo junto à opinião pública, uma grande preocupação dos governos em todas as esferas, conforme pontua Pinho (1990), e do governo Temer, em particular.

Em sua visada histórica acerca da propaganda de governo no desenvolvimento capitalista, Pêcheux (2011 [1979]) já ressaltava a importância dessas ações publicitárias 
desde a França do Armistício, como trouxemos na epígrafe deste artigo. Ainda voltando-se ao cenário francês pós-maio de 68, como exemplo, Pêcheux afirma que no modo de produção capitalista, entre as décadas de 1960 e 1980, o Estado passa a ter seu funcionamento calcado sob o que o autor chama de "uma nova fase da política do performativo" (PÊCHEUX, 2011 [1979], p. 91), fase em que a propaganda de governo começa a funcionar de forma a substituir a prática política.

No corpus que aqui trazemos para análise, pensamos que a propaganda funciona discursivamente de modo a tentar produzir efeitos de sentidos outros para práticas políticas que não necessariamente atendem a interesses educacionais. A propaganda transforma a gestão governamental sobre a educação em um produto, que necessariamente precisa ser apreciado pela população, ainda que não traga qualquer benefício efetivo a ela. Parafraseando a afirmação de Pêcheux (2011 [1979], p. 91), acerca de uma das direções tomadas pelas propagandas de governo, trata-se de "explicar" à população "que, com o programa comum" de educação anunciado, ela será beneficiada, "ainda que não tenha outra coisa a fazer senão” aceitá-lo.

Ainda como parte das condições de produção do discurso que propomos analisar, cabe-nos pensar a respeito da legislação que regula a prática de propaganda do governo no Brasil, na atualidade. Pensamos, assim, nas circunstâncias imediatas desse dizer que, conforme Orlandi (2001), determinam igualmente o modo como os sentidos se produzem.

As práticas publicitárias do governo federal são determinadas pela Instrução Normativa no 1, de 27 de julho de 2017, anunciada como uma norma destinada a abordar "os conceitos da comunicação do Poder Executivo Federal, previstos no Decreto no 6.555/20o8”4 (BRASIL, 2017c). Ao tratar da Comunicação Pública, a Instrução Normativa a define do seguinte modo:

\footnotetext{
${ }^{4}$ Essa Instrução foi promulgada em substituição à Instrução Normativa $n^{\circ} 5$, de 6 de junho de 2011 (BRASIL, 2011), passando a determinar os variados tipos de propagandas de que pode se valer o governo de Michel Temer. Comparativamente, as duas instruções normativas especificam as mesmas práticas comunicacionais, a saber: Comunicação Pública, Publicidade, Publicidade Institucional, Publicidade de Utilidade Pública, Publicidade Mercadológica, Publicidade Legal, Promoção, Patrocínio, Relações com a Imprensa, Relações Públicas e Comunicação Digital. A diferença que observamos entre ambas é que na Instrução em vigência são especificados em separado os itens: Comunicação Pública e Comunicação Social do Poder Executivo Federal (que é acrescentado na Instrução em vigor). Esse último item, por sua vez, comporta todos os demais, mas elencados em ordem diferente daquela adotada na Instrução de 2011.
} 
Comunicação pública: entende-se como aquela realizada exclusivamente em prol do interesse público, com vistas a garantir a cidadania, o direito à informação, à livre expressão de pensamento e a participação do cidadão no debate de assuntos de relevância política, econômica e social e de temáticas relacionadas à condição humana e à vida em sociedade. (BRASIL, 2017c).

Nessa definição de Comunicação Pública que norteia a Instrução Normativa, temos a associação das práticas de comunicação a serem mobilizadas pelo governo a princípios democráticos, como o "interesse público", a garantia à "cidadania” e ao “direito à informação", bem como à participação nas discussões acerca da gestão pública, em suas variadas esferas. Desse modo, produz-se para a comunicação efeitos de sentidos de um direito da população, que asseguraria "exclusivamente" os interesses comuns.

Na sequência da Instrução, ao especificar a Comunicação Social do Poder Executivo Federal, esses sentidos são retomados na afirmação de que tal comunicação "será realizada por meio da integração e sinergia das ferramentas de comunicação capazes de disseminar, esclarecer e fomentar conteúdos e temas relacionados à atuação do Governo Federal e de interesse da sociedade” (BRASIL, 2017c). Dentre as ferramentas possíveis a serem mobilizadas pelo governo, são elencadas quatro formas de Publicidade, a saber: Institucional, de Utilidade Pública, Mercadológica e Legal.

Em nosso corpus, entendemos que funciona a Publicidade Institucional que, por sua vez, é definida do seguinte modo:

\footnotetext{
Destina-se a divulgar atos, ações, programas, obras, serviços, campanhas, metas e resultados dos órgãos e entidades do Poder Executivo Federal, com o objetivo de atender ao princípio da publicidade, de valorizar e fortalecer as instituições públicas, de estimular a participação da sociedade no debate, no controle e na formulação de políticas públicas e de promover o Brasil no exterior; (BRASIL, 2017C).
}

A Publicidade Institucional, conforme a legislação, serve prioritariamente à divulgação das ações governamentais e o seu primeiro objetivo consiste em "atender ao princípio da publicidade". Tais princípios são desdobrados, como expomos a seguir:

- de valorizar e fortalecer as instituições públicas,

- de estimular a participação da sociedade no debate, no controle e na formulação de políticas públicas 
- e de promover o Brasil no exterior;

Com esses desdobramentos, vemos funcionar um processo de deslizamento de sentidos, no qual "atender ao princípio da publicidade” é associado, inicialmente, a "valorizar e fortalecer as instituições públicas"; posteriormente, a "estimular a participação" popular nas discussões concernentes à gestão pública; e por fim, à promoção do "Brasil no exterior". À prática publicitária de divulgação das ações do governo é projetada a imagem de valorização e fortalecimento das instituições públicas, bem como a imaginária participação social nas decisões governamentais e a promoção do Brasil no exterior. Desse modo, entende-se que não são as ações políticas do governo, mas as suas ações de publicidade institucional que seriam capazes de assegurar o alcance de tais objetivos. Retomando uma vez mais a reflexão proposta por Pêcheux (2011 [1979]), trata-se de um caso exemplar de como a propaganda de governo passa a funcionar de forma a substituir a prática política.

É a partir dessas considerações históricas acerca do desenvolvimento das propagandas de governo, bem como das condições de produção do discurso sobre a publicidade de governo em nossa conjuntura sócio-histórica que passamos a analisar os sentidos em circulação na propaganda sobre a BNCC, o que exige pensarmos no processo de elaboração desse documento, bem como nos dizeres que ali se apresentam.

\section{A criação de uma base nacional curricular}

A BNCC se apresenta como "um documento de caráter normativo que define o conjunto orgânico e progressivo de aprendizagens essenciais que todos os alunos devem desenvolver ao longo das etapas e modalidades da Educação Básica,” (BNCC, 2017a, p. 7, negrito do documento). Mais adiante ela ainda se auto define como "referência nacional para a formulação dos currículos dos sistemas e das redes escolares dos Estados, do Distrito Federal e dos Municípios e das propostas pedagógicas das instituições escolares" (BNCC, 2017a, p. 8). 
O documento se enquadra no que Freitas (2015) denomina instrumentos educacionais: "instrumentos que regem o fazer docente e instituem o lugar social e discursivo do professor, legitimando seu discurso e submetendo-o às estruturas do Aparelho Ideológico de Estado de que faz parte a escola” (FREITAS, 2015, p. 43), categoria que engloba, além da normatização oficial (leis, portarias, parâmetros, projetos, currículos), os sistemas de avaliação "que balizam a educação pela verificação de conteúdos sistematizados reprodutíveis" (FREITAS, 2015, p. 43). A produção e circulação desses instrumentos, por sua vez, se manifesta na produção dos instrumentos pedagógicos "enquanto estes são instrumentos utilizados (ou produzidos) pelo professor, aqueles necessariamente o precedem, instituindo o lugar a ser ocupado por ele, e determinando o seu dizer" (FREITAS, 2015, p. 43).

Os instrumentos educacionais de governo, portanto, participam de uma rede discursiva em que se articulam e se produzem concepções juridicamente estabelecidas para determinar os lugares a serem ocupados por professores e alunos, traçando o que Pfeiffer (2001) denomina "sujeito urbano escolarizado". Segundo a autora, o sujeito urbano escolarizado decorre do trabalho da escola, "que se coloca na responsabilidade de produzir a consciência da língua e da cidadania no aluno que ainda se encontra como “cidadão e autor em embrião”, e termina por produzir "um simulacro de ambos" (PFEIFFER, 2001, p. 31), o que resulta em um não lugar de inscrição histórica dos sentidos.

Tais instrumentos funcionam, assim, sob a contradição constitutiva do próprio lugar do Estado na formação social capitalista: um Estado sujeito às forças econômicas, refém de sua própria ordem no que diz respeito à produção e manutenção das condições de vida de sua população e da obrigação de garantia e ampliação das riquezas dos que governam essas forças, nos planos nacional e internacional. É esse Estado que produz os instrumentos educacionais, na necessidade de gestão do aparelho escolar, e produz a propaganda desse instrumento; logo, tais contradições neles se manifestam e produzem os efeitos que aqui analisamos.

Essa relação entre propaganda, aparelho escolar e formas de assujeitamento já chamava a atenção de Pêcheux (2011 [1979]) no funcionamento da formação social capitalista, quando, ao denominar de "via 1" o Modo de Produção Capitalista 
americano, em que "a ideologia jurídica do contrato livre e igual" (p. 8o-81) faz das "leis de mercado" a mola essencial da divisão de classes, a contrasta à via prussiana que, por sua vez, é herdeira de estruturas da sociedade feudal e apresenta maior proeminência do Estado. Assim, Pêcheux ressalta que:

esta diferença histórica não deixa evidentemente de ter consequências sobre as próprias formas de assujeitamento político e ideológico dos indivíduos: a dominação da ideologia jurídica própria à via 1 traz certas consequências em seu funcionamento material, por exemplo, à ligação entre o aparelho político e o aparelho escolar; as formas "americanas" da liberdade individual e do selfgovernnment vão juntas com as da educação, pondo em funcionamento certa concepção do Iluminismo ao contato com a vida, os fatos de experiência, aos quais a razão aplica suas regras de procedimentos; produzindo ao mesmo tempo este espaço da objetividade prática a que os Europeus têm o hábito de referir pelo duplo termo de liberalismo e de pragmatismo. (PÊCHEUX, 2011 [1979], p. 81).

A BNCC, portanto, não cria, mas opera, materializa, reproduz e assevera o jogo de contradições, que produz/especifica esse lugar de sujeito moderno, urbano e escolarizado (Cf. PFEIFFER, 2001): livre por direito e subalterno às condições econômicas que sustentam a própria formação do Estado; autônomo e responsável por seu próprio (in)sucesso; e subjugado pelas condições de trabalho da ordem capitalista, que lhe são apresentadas como valores universais a priori. Trata-se do sujeito individualizado pelo Estado, e por ele mesmo universalizado pelo caráter homogeneizante reprodutivo manifesto nas leis e, por conseguinte, nos objetivos de aprendizagem propostos na Base Curricular.

A formulação da BNCC conta com a participação de respeitados especialistas nas áreas de conhecimento que a sustentam, bem como com sugestões, críticas, reformulações e análises de representantes de educadores das diversas regiões, como registrado em sua apresentação e nos dizeres que circulam sobre ela nas páginas do Ministério da Educação e dos organismos que apoiam a construção desse instrumento. Isso não pode impedir, no entanto, que como instrumento de Estado, tais contribuições se articulem para os interesses de manutenção da formação social capitalista. Nisso reside o funcionamento da contradição: movimento em que os interesses das classes exploradas "coincidem" com os interesses das classes dominantes; em que, na impossibilidade do todo, se recortam os pontos de intercessão, 
e num efeito de bricolagem se alinham interesses opostos, numa suposta conciliação que atende aos interesses da nação.

Avanço na democratização da educação. Um balizador seguro para o exercício da profissão. Um mal necessário. Desperdício conceptual incapaz de atingir a prática docente. Instrumento de controle e tolhimento da atividade do professor. Muitos e diferentes são os dizeres sobre tal documento nas diversas instâncias por ele afetadas; efeito da contradição que o constitui e indicador das diferentes posições sujeitos que assumem seus leitores na produção de sentidos em circulação; sintomas do funcionamento contraditório do Estado capitalista, materializado em suas ações.

Ao pensar, assim, a constituição dos instrumentos educacionais como instrumentos de Estado, sujeitos ao funcionamento de suas contradições, podemos apontar como marcas desse funcionamento a existência dos documentos e das manifestações que se levantam em defesa da BNCC (dos quais destacamos a propaganda governamental de que trata esse artigo) e também daqueles que se levantam para apontar suas falhas e a perversidade de seu funcionamento. Nesse último grupo, encontram-se, por exemplo, manifestos expedidos pela Associação Nacional de Pós-Graduação e Pesquisa em Educação (ANPED), pela Associação Brasileira de Currículo $(\mathrm{ABdC})$, que congrega os profissionais e estudantes que realizam atividades de pesquisa e/ou docência e extensão no campo do Currículo, e pela Comissão Permanente de Formação de Professores da Universidade Estadual de Campinas (CPFP/Unicamp) ${ }^{5}$, que congrega docentes representantes de todos os 22 cursos de Licenciatura da Unicamp que, em conjunto com centenas de publicações de especialistas de diversas áreas, condenam as concepções de currículo e as falhas na execução política de formulação da Base.

Entre as críticas que se fazem à BNCC - que é apresentada no próprio texto como legatária da Lei de Diretrizes e Bases da Educação Nacional (LDB) 9394/96 (BRASIL, 1996), dos Parâmetros Curriculares Nacionais de Educação (PCNs), e do Plano Nacional de Educação -, destaca-se a ampla participação do setor privado na condução de sua formulação. Marsiglia et al. (2017) enfatizam o fato de, nesse processo,

\footnotetext{
${ }^{5}$ Tais documentos podem ser acessados nos seguintes links: http://www.anped.org.br/sites/default/files/images/a_anped_e_a_bncc_versao_final.pdf http://www.ccg.unicamp.br/files/cpfp/BNCC-Manifestao-Unicamp-2017_09_11.pdf
} 
além de membros de associações científicas, dos secretários e dirigentes municipais e estaduais de educação, participam "fundamentalmente representantes dos aparelhos privados de hegemonia da classe empresarial que compõem a ONG Movimento pela Base Nacional Comum” (MARSIGLIA et al., 2017, p. 108). Os autores destacam, como integrantes dessa ONG, entidades como "Fundação Itaú Social, Fundação Lemann, Fundação Roberto Marinho, Instituto Unibanco, Instituto Ayrton Senna, Instituto Natura, CENPEC” (MARSIGLIA et al., 2017, p. 114).

Ancorados em uma abordagem histórico-crítica de currículo, os autores destacam ainda, na BNCC, as ausências a) da "noção de historicidade e provisoriedade do conhecimento" (MARSIGLIA et al., 2017, p. 111), b) “da interdependência entre o processo de seleção, organização e sistematização lógica e metodológica do conhecimento e a organização das condições espaço-temporais da escola" (MARSIGLIA et al., 2017, p. 111); e c) "de ao menos um parágrafo que discuta o papel do professor e a questão do ensinar" (MARSIGLIA et al., 2017, p.118). Para os autores, tratase de um projeto que se sujeita às forças de mercado, uma vez que enfatiza "as 'habilidades', as 'competências', os 'procedimentos' e a 'formação de atitudes”. E prosseguem: “o objetivo dessa formação é preparar os filhos da classe trabalhadora para o mundo do trabalho informal e precarizado, compatível com as novas demandas do capital para este século, voltadas para a acumulação 'flexível”' (MARSIGLIA et al., 2017, p. 119).

É nesse espaço de críticas amplamente difundidas no contexto acadêmico e dos questionamentos estabelecidos aos organizadores da BNCC que o documento foi homologado, possuindo caráter normativo e vinculante às políticas de formação de professores das universidades. A propaganda governamental sobre a BNCC surge, assim, como estratégia de solidificação das ideias que apresenta de construção de uma imagem positiva do governo e de resposta às criticas que vem sendo feitas ao documento.

Em sua análise, Pêcheux (2011 [1979]) salienta a produção da propaganda governamental na constituição do sujeito na formação social capitalista, apontando o modo como tais contradições se materializam nessas formulações. Segundo o autor, nas condições do assujeitamento político e ideológico do capitalismo do após-guerra, 
uma nova articulação se instituía entre o "racional" e o "irracional", entre a objetividade dos fatos, dos dados empíricos, etc, e a subjetividade das experiencias dos testemunhos, entre o sério das discussões entre expertes e o imediatismo das "informações" distribuídas ao homem da rua, entre os mecanismos impessoais da administração capitalista moderna, e a personalização da vida política pelas “mass-médias” (PÊCHEUX, 2011 [1979], p. 87).

Nesse funcionamento, se pulverizam propagandisticamente anseios, projeções, fundamentações, opiniões... dizeres que procuram silenciar as contradições e estabelecer um sentido único, hegemônico, silenciador. Com a propaganda dos atos de governo, todo funcionamento discursivo da BNCC transfere-se do jurídico e do administrativo ao midiático, num poder de circulação que excede qualquer debate teórico sobre a pertinência do mesmo. É desse funcionamento que tratamos na próxima seção.

\section{A propaganda sobre a BNCC}

Nesta seção, voltamo-nos a algumas reflexões analíticas sobre o nosso corpus, constituído pela propaganda em vídeo com o título "Base Nacional Comum Curricular" (BRASIL, 2017b), disponibilizada na página no YouTube do Ministério da Educação. Em nosso gesto de análise, procuramos compreender como a combinação entre o texto narrado, as imagens e as legendas, ao converter a BNCC em produto educacional a ser adquirido pelo telespectador, produz o efeito de que essa será capaz de finalmente estabelecer a equidade no campo educacional. No percurso analítico que empreendemos, avançamos em direção ao batimento entre a produção de sentidos na propaganda analisada e a reflexão de Pêcheux (2011 [1979]) sobre o modo de produção da propaganda governamental na formação social capitalista.

Em 30 segundos de narrativa em off, a propaganda sobre a BNCC apresenta o documento como capaz de uma intervenção sem precedentes na história educacional brasileira. Nos dizeres nela narrados: 
O Brasil terá, pela primeira vez, uma Base Nacional Comum Curricular! O documento é democrático e respeita as diferenças. Com a Base, todos os estudantes do país, de escola pública ou particular, terão os mesmos direitos de aprendizagem. Isso é bom: se a base da educação é a mesma, as oportunidades também serão! Ministério da Educação - Governo Federal (BRASIL, 2017b, transcrição nossa).

O texto é narrado sobre imagens de crianças, dispostas em telas divididas, que executam simultaneamente ações padronizadas, legendadas no inferior da tela pelos dizeres: "NORTE/SUL; EDUCAÇÃO INFANTIL E ENSINO FUNDAMENTAL; CENTRO OESTE/SUDESTE; SUDESTE/SUL; NORDESTE/SUDESTE; SAIBA MAIS EM: basenacionalcomum.mec.gov.br".

O jogo entre imagens, legenda e narração produz o efeito harmônico, coeso e estabilizado que caracteriza a propaganda, sem espaço para dúvidas ou refutações: "isso é bom" é o que se diz, e bom é o que se mostra. No desejo de representação das diferentes regiões e de apagamento do contraste que as caracteriza, pela representação do que se considera "bom", são produzidas legendas que evidenciam o lugar do Sul e Sudeste no imaginário de desenvolvimento, de modo que todos os comparativos produzidos têm como referência essas regiões, em especial o Sudeste, que apenas não é evocado na primeira legenda (NORTE/SUL), expressão que, por sua vez, produz também o efeito de totalidade.

Os recortes de vídeo que compõem a propaganda exibem crianças que acordam em quartos decorados, trajando pijamas, sob o conforto de cobertores e edredons. Retratam tais crianças em seus hábitos de higiene matinal que ocorrem em banheiros com paredes revestidas de cerâmicas de diferentes cores e motivos. Na sequência, essas crianças tomam café da manhã em mesas postas com xícaras e copos cerâmicos, em cozinhas decoradas, limpas e organizadas. Trajando uniformes limpos e mochilas organizadas, acompanhadas pelas figuras maternas, as crianças caminham por ruas e calçadas arborizadas, urbanizadas. Um novo corte mostra um escadão, que remete à figura do morro, e nele, casas com boa infraestrutura e acabamento figuram ao fundo. Na imagem ao lado, a estrada de chão remete ao ambiente rural, onde uma criança é acompanhada da figura paterna, que traja calça jeans, tênis e camisa de tecido. As salas de aula são limpas e os corredores das escolas, amplos e iluminados. Tudo é muito simples, limpo e agradável. 
Conforme preconiza Orlandi (2001), o discurso também se constitui pelo nãodito, que produz seus efeitos no dizer. Em seus termos, os "sentidos têm a ver com o que é dito ali mas também em outros lugares, assim como com o que não é dito, e com o que poderia ser dito e não foi” (ORLANDI, 2001, p. 30). O dizer da propaganda funciona, assim, também em relação ao não-dito e aos apagamentos que produz. No imagético da propaganda, produz-se um imaginário que esconde e atenua a pobreza, um jogo entre o desejável e o mostrável. No Brasil de contrastes bonitos produzido pela propaganda não há espaço para crianças que dividem a cama com outros irmãos, que vivem em casas sem as mínimas condições de habitação e que tomam na escola sua primeira refeição do dia (quando não as únicas). Na pobreza alegre da produção televisiva, as crianças de meio urbano ou rural são conduzidas por seus pais, que não se submetem a condições degradantes de trabalho e podem acompanhar a vida escolar de seus filhos.

Apaga-se a pobreza, e com isso, ambiguamente, afirma-se a quem se destinam as políticas educacionais, ao mesmo tempo em que se afirma que esse (o fim da pobreza) será o efeito de sua implementação. Apaga-se a conjuntura para dizer que, uma vez oferecida a todos "a mesma base curricular", iguais serão as condições de aprendizagem; que cumprido está o papel do Estado na oferta de educação de qualidade (agora que todos os alunos terão a "mesma base" das escolas particulares) e que qualquer deficiência de aprendizagem, qualquer fracasso escolar só pode, de agora em diante, ser atribuído ao aluno (talvez ao professor), pois a eles foram ofertadas, via BNCC, as mesmas oportunidades. Se ainda assim persistir a pobreza, esta será, por consequência, fruto do desinteresse, da incapacidade, da índole; pois com a homologação da Base, ofertadas estão as mesmas condições.

Ao dizer sobre a educação, o governo toma posicionamento na luta de classes: no apagamento das condições de vida de grande parte dos alunos de escolas públicas, irrompem as "condições de exercício das propagandas políticas, através de uma longa série de tentativas de emprestar, tomar a palavra, desviar, virar, desnaturar as bases práticas do adversário de classe" (PÊCHEUX, 2011 [1979], p. 82). A estratégia utilizada, é, portanto, semelhante à apontada por Pêcheux no Stalinismo, "obstinada em evacuar qualquer contradição e a mascarar a existência das relações de classes: ela usa uma 
falsa aparência para contornar indefinidamente o que todo mundo sabe e que ninguém pode dizer" (PÊCHEUX, 2011 [1979], p. 86).

No imaginário de homogeneização do aluno de escola pública, não é a pobreza que gera o fracasso escolar, mas a ausência de uma base curricular unificada que seria a responsável por gerar a pobreza, afastada agora da realidade via implementação dessa documentação. Se as regiões apresentam diferentes índices de desenvolvimento, é necessário e suficiente aplicar nas regiões menos desenvolvidas a fórmula curricular utilizada no Sudeste, como enfatiza a legenda, como se mesmo nessa região fossem homogêneas as condições de aprendizagem e os resultados escolares.

Pêcheux (2011 [1979]) aponta como "formas de assujeitamento" da via capitalista 2 - Prussiana, que herda a memória do estado central monárquico - a imposição de “determinações à educação e ao exercício do direito” (PÊCHEUX, 2011 [1979], p. 86). É no funcionamento dessas determinações que a propaganda governamental age, enaltecendo como a aprovação de uma lei sobre a educação deve produzir efeitos na vida cotidiana, sem que, para isso, nenhuma outra política educacional seja proposta como meio de se realizar as ambições nela contidas. Contudo, se a propaganda re(produz) um imaginário ideal e sem rupturas, o autor também nos alerta que, no mascaramento de suas contradições, o Estado "diz frequentemente verdades sobre si mesmo sem percebê-lo, em seus lapsos e denegações” (PÊCHEUX, 2011 [1979], p. 86). É assim que podemos ler nos dizeres institucionais uma resposta às críticas tecidas à BNCC.

Em sua reflexão, Pêcheux (2011 [1979]) chama a atenção para a propaganda nacional socialista, que atuava "explorando sistematicamente a ambiguidade do termo 'povo' para mobilizar as massas populares em nome da Nação alemã, para subjugar o povo (com p minúsculo) em nome do Povo (com P maiúsculo)" (PÊCHEUX, 2011 [1979], p. 85, itálico do autor). No cenário brasileiro, diante das críticas tecidas à implementação da BNCC, o governo afirma que “o documento é democrático", em referência à coletividade atribuída à sua construção (BNCC, 2017a, p. 05). Na afirmação de um "documento democrático", silenciam-se as vozes dos que criticam seu teor, reservando-lhes o lugar de antidemocráticos; “democrático" seria aqui expressão da vontade do povo, num processo cuja gestão foi concluída num governo que não expressa tal vontade. 
Tudo ocorre como se a participação de especialistas e as audiências a que foi submetido o documento pudessem apagar a composição antidemocrática do governo, e desse ao texto a inequívoca manifestação do desejo de todos os que dela participaram (a vontade do povo); como se os cortes e silenciamentos, que constituem qualquer produção na língua, fossem também resultado de um processo de construção coletiva, e não das forças que conduzem o processo e determinam o que deve ser cortado e o que deve ser mantido.

No Estado capitalista, e assim, na construção da BNCC, a propaganda governamental participa de um jogo que tende por fazer prevalecer, em nome do povo, os desígnios da classe dominante. Retornando uma vez mais ao que nos diz Pêcheux: “O 'liberalismo totalitário' (segundo expressão de Chomsky) soube colocar no ponto uma nova gestão da subjetividade na qual o sujeito contribui ativamente para seu assujeitamento, através de um sinistro jogo de palavras sobre o termo liberdade" (PÊCHEUX, 2011 [1979], p. 88), ou, em nosso caso, sobre o termo “democrático".

É assim, na esteira de dizeres que buscam estabilizar sentidos para a BNCC, que a voz do locutor é entrecortada por falas dos personagens que ilustram a propaganda. Na retratação de escolas de diferentes regiões sob o efeito da homogeneização sugerida pelo vídeo, uma professora e um professor, em diferentes quadros do vídeo, dizem simultaneamente: "Hoje a aula é sobre cidadania" -informando-nos de que o termo “cidadania” consta da BNCC, ao mesmo tempo que produz para o vídeo a que assistimos o efeito de ser ele mesmo uma aula. Desse modo, podemos questionar: $\mathrm{O}$ que dele se deve aprender? Ao que podemos responder: aprender que a BNCC é boa, democrática e capaz de garantir a condição de cidadania, termo que evoca o juridismo do Estado de direito. Como afirma Pêcheux:

A virada de outro lado da propaganda liberal burguesa (fundada na Declaração dos Direitos do Homem, o papel motor do Sujeito de Direito, das consciências e das "ideias que levam o mundo") conduzirá assim o movimento operário a seguir à risca o juridismo parlamentar e a desenvolver uma propaganda educativa fundada na tomada de consciência, uma espécie de política proletária da difusão do Iluminismo e da Verdade, aderindo ao juridismo burguês, mais ainda do que a própria burguesia, veículo de muitas ilusões... (PÊCHEUX, 2011 [1979], p. 82, reticências do autor). 
Na análise de Pêcheux (2011 [1979]), o discurso do juridismo burguês toma a propaganda como educativa, difusora da Verdade, com V maiúsculo, incontestável, democrática, boa. No discurso propagandístico sobre educação que ora analisamos, dizer cidadania é dizer sobre direitos, sobre as condições que se devem cumprir para que se tenha direitos, para que se exerça a cidadania. A educação se insere, assim, no jurídico, como um direito garantidor de direitos, garantida pelo direito. A BNCC é uma lei, possui caráter normativo, e sua propaganda se filia ao discurso jurídico, trazendo deste, além do termo "cidadania”, o próprio termo "direitos". No entanto, ao cuidar das relações entre o discurso e a lógica na obra de Frege, Pêcheux (1997a [1975]) nos alerta:

O jurídico não é, pura e simplesmente, um "domínio de aplicação" da Lógica, como pensam os teóricos do formalismo jurídico (Kelsen, etc.), mas sim que há uma relação de simulação constitutiva entre os operadores jurídicos e os mecanismos de dedução conceptual, especialmente entre a sanção jurídica e a consequência lógica. (PÊCHEUX, 1997a [1975], p. 98).

Diferentemente de uma relação lógica e estabilizada que é almejada no discurso jurídico, este está sujeito às falhas e contradições que constituem a língua, e se apresenta sempre como espaço de interpretação. É nesse espaço de interpretação que podemos encontrar no juridismo as marcas linguísticas de um projeto que, sob uma projeção de construção democrática, inscreve em suas contradições os desígnios das forças de mercado a que se sujeita o governo, produzindo a simulação constitutiva de que nos diz Pêcheux (1997a [1975]).

Trazemos, assim, ao foco de nossa análise, a construção discursiva que define, na propaganda, o funcionamento da BNCC: "todos os estudantes do país, de escola pública ou particular, terão os mesmos direitos de aprendizagem.” (BRASIL, 2017b). Ao evocar o discurso do direito, a propaganda reproduz a inovação jurídica trazida pela BNCC: a ideia singular de "Direito à educação", constitucionalmente prevista, é fragmentada na BNCC pela pluralidade dos “direitos de aprendizagem”. Desse modo, o que é a todos garantido não é o todo, mas o fragmento, numa materialização do que já é apontado na análise de Marsiglia et al. (2017) como uma tendência que se instala desde os anos 1990, de "uma perspectiva de educação seletiva e minimalista para os que provavelmente vão exercer trabalho simples durante toda a vida, priorizando a 
educação básica e se restringindo às 'necessidades básicas de aprendizagem”" (MARSIGLIA et al., 2017, p. 113).

A fragmentação do direito à educação em “direitos de aprendizagem” constitui, assim, uma negação do direito; ao elencar os direitos de aprendizagem, afirma-se que nem todos terão direito a todos os saberes. Há no processo de constituição das diferentes versões da BNCC um deslizamento de formulações em que "necessidades de aprendizagem" desliza para "expectativas de aprendizagem” até a formulação que institui como direito apenas o saber necessário, apagando o direito à educação plena, jamais ofertada pelo Estado, e que agora, fraturada pela lei que institui a BNCC, figura como elemento central da propaganda que enaltece a fragmentação do direito como uma conquista de direitos.

$\mathrm{Na}$ aula de cidadania em que se converte a propaganda da BNCC figura um quadro de direitos respeitados; de moradia, higiene, alimentação, tutela e estruturação digna do espaço escolar. Aos que se resguardam esses direitos, também serão provavelmente ofertados, para além dos "direitos de aprendizagem" de que trata a BNCC, o direito de fato a uma concepção holística de educação. Contudo, aos que se negam tais direitos, também se espera que até a base fragmentada proposta na BNCC seja negada. Num Estado comprometido com o mercado, a única base comum da educação é a legislação, que, a não ser na propaganda governamental, não coincide com as reais condições de existência de grande parte do público escolar brasileiro.

\section{Considerações finais}

Iniciamos o nosso percurso neste artigo com o propósito de refletirmos acerca do funcionamento da propaganda governamental no Brasil, durante o governo de Michel Temer, voltando-nos especificamente à análise discursiva da propaganda sobre o lançamento da BNCC para o ensino fundamental, posta em circulação na mídia no ano de 2017. 
Após nos voltarmos às condições de produção do discurso publicitário governamental, por meio da retomada da legislação regulamentadora das práticas publicitárias do governo no país, bem como aos modos de constituição histórica do discurso publicitário, empreendemos gestos de análise nos quais buscamos compreender como as diferentes materialidades significantes em funcionamento na propaganda, tomada como corpus, produz para a BNCC efeitos de sentidos que tornam a educação um produto, e confere ao documento o imaginário de promoção da equidade no campo educacional.

Ao nos determos sobre a reflexão de Pêcheux (2011 [1979]) acerca do modo de produção da propaganda governamental na formação social capitalista e ao seu funcionamento, buscamos mostrar em nossos recortes analíticos como, na propaganda da BNCC, produz-se o efeito de que, pelas oportunidades que trará - sustentadas em um imaginário de democracia e cidadania - ela poderá reverter os quadros de desigualdade social que caracterizam o país.

$\mathrm{Na}$ epígrafe com a qual começamos, trouxemos de Pêcheux uma afirmação a respeito do modo como a propaganda de governo, em um momento específico da história, deixou de ser um "negócio militar" para se tornar "a preocupação número um” do Estado (PÊCHEUX, 2011 [1979], p. 74); o que não se deu espontaneamente, mas por força de uma conjuntura sócio-histórica de sobreposição do mercado às práticas políticas. Na conjuntura brasileira atual, temos a propaganda governamental sobre a educação fazendo circular dizeres que, embora apontem para a imaginária igualdade nas oportunidades, seguem a serviço do mercado e da manutenção das diferenças.

\section{Referências}

BRASIL. Secom. Execução Contratual de Publicidade. Disponível em: $<$ http://sistema1.planalto.gov.br/secomweb2/demanda/execucaocontratual>. Acesso em: 17 jul. 2018.

. Secretaria-Geral. Instrução Normativa no 1, de 27 de julho de 2017. Diário Oficial da União. Seção 1, no 144. 28 jul. 2017. 2017c. Disponível em: 
<http://pesquisa.in.gov.br/imprensa/jsp/visualiza/index.jsp?data=28/o7/2017\&jornal=1 \&pagina=7\&totalArquivos=144>. Acesso em: 18 jul. 2018.

. Base Nacional Comum Curricular (BNCC). Brasília, MEC/CONSED/ UNDIME, 2017a. Disponível em: <http://basenacionalcomum.mec.gov.br/download-da-bncc>. Acesso em: 18 jun. 2018.

. Instrução normativa Secom no 5 , de 6 de junho de 2011. Disponível em: <http://www.secom.gov.br/orientacoes-gerais/publicidade/2011-in-o5-conceito-deacoes-de-comunicacao.pdf>. Acesso em: 18 jul. 2018.

. LDB. Lei 9394/96 - Lei de Diretrizes e Bases da Educação Nacional. 1996. Disponível em: <www.planalto.gov.br/CCIVIL_03/Leis/L9394.htm>. Acesso em: 25 jun. 2018.

FREITAS, R.A. Língua e ensino: objetos paradoxais: a contradição no ensino de língua portuguesa. Dissertação (mestrado) - Universidade Federal Fluminense, Instituto de Letras. Niterói-RJ: 2015.

MATTOS, H.; BESSONE, T.; MAMIGONIAN, B.G. (Orgs.). Historiadores pela democracia: o golpe de 2016 e a força do passado. São Paulo: Alameda, 2016.

MARSIGLIA, A.C.G.; PINA, L.D.; MACHADO, V.O.; LIMA, M. A Base Nacional Comum Curricular: um novo episódio de esvaziamento da escola no Brasil. Germinal: Marxismo e Educação em Debate, v. 9, p. 107-121, 2017.

ORLANDI, E. Análise de discurso. Princípios e procedimentos. 3 ed. Campinas: Pontes, 2001.

PÊCHEUX, M. [1979]. Foi “propaganda” mesmo que você disse?. Trad. Eni Orlandi. In: ORLANDI, Eni (Org.). Análise de Discurso: Michel Pêcheux. 3. ed. Campinas, SP: Pontes, 2011. p. 73-92.

. [1975]. Semântica e discurso: uma crítica à afirmação do óbvio. 3 ed. Campinas: Editora da Unicamp, 1997a.

. [1969]. Análise Automática do Discurso (AAD-69). In: GADET, Françoise; HAK, Tony. Por uma análise automática do discurso: uma introdução à obra de Michel Pêcheux. Trad. Bethania Mariani [et al.]. 3. ed. Campinas, SP: Editora da Unicamp, 1997b. p. 61-161. 
PFEIFFER, C.R.C. Cidade e sujeito escolarizado. In: ORLANDI, E.P. (Org.). Cidade atravesada: os sentidos públicos no espaço urbano. Campinas-SP, Pontes Editores, 2001. p. 29-33.

PINHO, J.B. Propaganda institucional: usos e funções da propaganda em relações públicas. São Paulo: Summus Editorial, 1990.

PMDB. Uma ponte para o futuro. 2015. Disponível em: <https://www.fundacaoulysses.org.br/wp-content/uploads/2016/11/UMA-PONTEPARA-O-FUTURO.pdf>. Acesso em: 20 jul. 2018.

VERDÉliO, A. Governo Temer recebe aprovação de $6 \%$ da população; $74 \%$ desaprovam. Agência Brasil. 20 dez. 2017. Disponível em: <http://agenciabrasil.ebc.com.br/geral/noticia/2017-12/governo-temer-recebeaprovacao-de-6-da-populacao-74-desaprovam>. Acesso em: 18 jul. 2018.

\section{Corpus}

BRASIL. Base Nacional Comum Curricular. Ministério da Educação. 2017b. Youtube. Disponível em: <https://www.youtube.com/watch?v=Fbz-cpctıW4>. Acesso em: 17 jul. 2018.

\section{Recebido em 26/o8/2018.}

Aprovado em 07/11/2018. 